\title{
Almond Consumption Is Associated with Better Nutrient Intake, Nutrient Adequacy, and Diet Quality in Adults: National Health and Nutrition Examination Survey 2001-2010
}

\author{
Carol E. O'Neil ${ }^{*}$, Theresa A. Nicklas ${ }^{2}$, Victor L. Fulgoni III ${ }^{3}$ \\ ${ }^{1}$ Louisiana State University Agricultural Center, Baton Rouge, LA, USA \\ ${ }^{2}$ USDA/ARS Children's Nutrition Research Center, Department of Pediatrics, Baylor College of Medicine, \\ Houston, TX, USA \\ ${ }^{3}$ Nutrition Impact, LLC, Battle Creek, MI, USA \\ Email: *coneil1@lsu.edu, tnicklas@bcm.edu,VIC3RD@aol.com
}

Received 11 March 2016; accepted 3 June 2016; published 6 June 2016

Copyright (C) 2016 by authors and Scientific Research Publishing Inc.

This work is licensed under the Creative Commons Attribution International License (CC BY).

http://creativecommons.org/licenses/by/4.0/

(c) (i) Open Access

\section{Abstract}

Purpose: The purpose of this study was to examine the association between almond consumption, the most widely consumed tree nut in the US, and nutrient intake, nutrient adequacy, diet quality, and weight/adiposity in adults. Methods: Data from adults $(\mathrm{N}=24,808), 19+$ years, participating in the NHANES 2001-2010 were used. The NCI method was used to estimate the usual intake of almonds and selected nutrients. Almond consumers were defined as those consuming any amount of almonds/almond butter. Percentages of the consumers/non-consumers below the Estimated Average Requirement (EAR) or above the Adequate Intake (AI) for select nutrients were determined. To assess significant differences for the percentage of almond consumers vs. non-consumers with intakes less than the EAR or above the AI, a Z-statistic for differences in population proportions was used. Covariate-controlled linear regression was used to determine differences in diet quality, measured by the Healthy Eating Index-2010 (HEI-2010), between the consumer groups. Body mass indices and waist circumference were assessed. $P$ was set at $p<0.01$. Results: Almond consumers were more likely to be non-Hispanic white, older, of higher income, more physically active, and were less likely to be a current smoker than non-consumers. Usual intake of almonds among

\footnotetext{
${ }^{*}$ Corresponding author.
}

How to cite this paper: O'Neil, C.E., Nicklas, T.A. and Fulgoni III, V.L. (2016) Almond Consumption Is Associated with Better Nutrient Intake, Nutrient Adequacy, and Diet Quality in Adults: National Health and Nutrition Examination Survey 2001-2010. Food and Nutrition Sciences, 7, 504-515. http://dx.doi.org/10.4236/fns.2016.77052 
consumers was $29.5 \pm 1.5 \mathrm{~g} /$ day. Usual intake of protein; dietary fiber; vitamins A, D, E, and C; thiamin; niacin; riboflavin; folate, calcium, copper, magnesium, iron, phosphorus, selenium, zinc, and potassium was higher in almond consumers. Almond consumers were less likely to be below the EAR for protein, vitamins A, D, E, B $B_{12}$, and C; riboflavin; calcium; copper; magnesium; iron; phosphorus; and zinc. They were also more likely to be above the AI for dietary fiber and potassium. Total HEI-2010 scores were approximately 15 points higher in almond consumers. Body mass indices and waist circumference measures were lower in almond consumers. Conclusions: Moderate consumption of almonds should be encouraged as part of a healthy diet.

\title{
Keywords
}

\author{
Almond Consumption, Tree Nut Consumption, Diet Quality, Nutrients, Nutrient Adequacy, Adults, \\ NHANES
}

\section{Introduction}

Almonds (Prunus dulcis), a type of tree nut, were one of the first tree nuts to be domesticated [1] and remain an important commercial crop. Native to Central Asia [1], California is now the most important supplier of almonds, producing over $80 \%$ of the world crop and virtually $100 \%$ of the United States (US) crop [2]. In 2012/ 2013, nearly 2 billion pounds of almonds were produced [2]. Per captia consumption of almonds in the US has increased from approximately 0.84 pounds in 2001/2002 to 1.4 pounds in 2009/2010 to 2 pounds in 2012/2013 [3]. Almonds are versatile, and can be consumed as a snack [4] [5] or as part of a meal—either alone or as part of a prepared dish; almond butter, almond oil, and almond milk can also be prepared from this tree nut.

Almonds are a rich source of nutrients that have been defined by the 2010 Dietary Guidelines for Americans (DGA) as a nutrient-dense food [6]. One serving (1 ounce/28.4 grams [g]) [7] provides 6 g protein (12\% of the Daily Value [DV]), $14.2 \mathrm{~g}$ total fat (88\% unsaturated), $3.5 \mathrm{~g}$ dietary fiber (14\% DV), $7.27 \mathrm{mg}$ vitamin E (36\% DV), $76 \mathrm{mg}$ calcium (8\% DV), $136 \mathrm{mg}$ phosphorus (14\% DV), and $208 \mathrm{mg}$ potassium (6\% DV) [8]. Almonds are also cholesterol and sodium free. According to the United States Department of Agriculture's nutrient data base, one serving of almonds also provides 164 kilocalories (kcals) [8]. However, it has been suggested recently that digestibility of fat from whole nuts (and peanuts, a legume) may be lower than previously thought [9] [10] and that the metabolizable energy content of almonds is actually only 129 kcals/ounce [11]. Almonds also provide phytochemicals including phenolic acids, phytosterols, and polyphenolic compounds such as flavonoids and proanthocyanidins, which have been associated with anti-oxidant and anti-inflammatory properties [12]-[14]. Because of this favorable nutrient/phytochemical profile, almonds are one of the tree nuts eligible for a qualified health claim regarding reducing cardiovascular disease risk [15].

Previous studies have shown that consumption of tree nuts has been associated with positive levels of nutrient intake, including the following short fall nutrients [6] [16]: dietary fiber, vitamin E, calcium, magnesium, and potassium [17] [18]. Tree nut consumers have also been shown to have lower intakes of saturated fatty acids (SFA) and higher intakes of mono-(MUFA) and Poly-Unsaturated Fatty Acids (PUFA) than non-consumers [17] [18]. Tree nut consumers have also been shown to have a better diet quality [17] than non-consumers. Conflicting results regarding the association of tree nut consumption and weight have been shown. Some epidemiologic studies have failed to show an association with weight [17] [19]; whereas, other epidemiologic studies and clinical trials have shown an inverse relationship between Body Mass Index (BMI) and tree nut consumption [20] [21]. Almonds, the most widely consumed nut in the US [3], have not been well studied in these regards; the authors were unable to find any recent epidemiologic studies that looked at the association of almond consumption and nutrient intake or adequacy, diet quality, or weight status. Long-term feeding studies have shown that almond consumers have higher intakes of vegetable protein, dietary fiber, MUFA, PUFA, $\alpha$-tocopherol, copper, and magnesium [22] and that long-term consumption of almonds was not adversely associated with BMI [23]-[26]. The purpose of this study was to determine whether there was an association between almond consumption and nutrient intake, nutrient adequacy, diet quality, and using a nationally representative sample of US adults. 


\section{Subjects and Methods}

\subsection{Study Population and Analytic Sample}

For these analyses, data from adults $19+$ years of age $(y)$ and older $(\mathrm{N}=24,808)$ participating in the National Health and Nutrition Examination Survey (NHANES) 2001-2010 were concatenated to increase sample size [27] [28]. Analyses included only individuals with dietary recalls determined to be reliable by the National Center for Health Statistics (excluded $n=147)$; females who were pregnant or lactating $(n=1128)$ were also excluded from the analyses. The NHANES has strict procedures that guarantee confidentiality and protect individual participants from identification [29]; Institutional Review Board review was not required [30].

\subsection{Demographics and Dietary Information}

Demographic information was obtained from the NHANES interview administered in the home [31]. Demographic information obtained from the questionnaire included gender, race/ethnicity, age, physical activity, current smoking status, and the poverty income ratio (PIR). The PIR is the ratio of family income to poverty, and was calculated by dividing individual or family income by the United States poverty guidelines specific to the survey year. The lowest value indicates individuals or families below the poverty line. This demographic information, along with alcohol intake, obtained through the 24-hour dietary recalls described below, served as covariates for the statistical analyses.

Dietary data were collected using two 24-hour dietary recalls using an automated multiple-pass method [32] [33]; the first recall was conducted in person by a trained interviewer in the Mobile Examination Center [34] and the second recall was conducted 3 - 10 days later via telephone [35]. Detailed descriptions of the dietary recalls and data collection are available in the NHANES Dietary Interviewer's Training Manual [36].

The USDA Food and Nutrient Database for Dietary Studies (FNDDS) [37] food codes for almond/almond butter (together referred to as "almonds" in this manuscript) were used to identify almond consumers: 42100100, 42101000, 42101100, 42101200, 42101210, 42101350, 42200500, and 42200600. Individuals were classified as almond consumers if any amount of almonds was ingested on either day of the recall. For each participant, daily total nutrient intakes from foods and beverages were obtained from the total nutrient intake files associated with each FNDDS data release. The Vitamin D Addendum to USDA FNDDS 3.0 [38] was used to determine vitamin D intake. Intake from supplements was not considered.

\subsection{Diet Quality as Determined by the Healthy Eating Index (HEI-2010)}

The HEI-2010 was used to determine diet quality [39] [40]. The SAS code used to calculate HEI-2010 scores was downloaded from the Center for Nutrition Policy and Promotion website [41]. Briefly, HEI-2010 was designed to evaluate all of the major food groups and major subgroups and nutrients to manage in the diet. The twelve HEI-2010 components were summed for a maximum score of 100 points. Components 10 (sodium), 11 (refined grains), and 12 (empty calories) are reverse scored, so the higher the score, the lower intake and the greater the contribution to diet quality.

\subsection{Anthropometric Measures}

Height, weight, and waist circumference (WC) were obtained according to NHANES protocols [42]. Body Mass Index (BMI) was calculated as body weight (kilogram) divided by height (meters) squared.

\subsection{Statistical Analyses}

Sampling weights and the sampling units and strata information, as provided by NHANES, were included in all analyses using SUDAAN v10.0 (Research Triangle Institute; Raleigh, NC) [27] [28]. Linear regression was used to determine differences between almond consumers and non-consumers for energy, macronutrients, HEI-2010, HEI-2010 subcomponents, and weight parameters. Least-square means and standard errors were calculated using PROC REGRESS of SUDAAN. For these analyses, most covariates were obtained from the questionnaire (or in the case of alcohol consumption the 24 hour dietary recalls), and were age, gender, ethnicity, poverty index ratio (one of three levels: 0 - 1.25, 1.25 - 3.5, >3.5) [31]; physical activity level (sedentary, moderate, or vigorous) [43], current smoking status, and alcohol consumption, which was obtained from the 24-hour dietary recall. For intake of total nutrients, total energy intake was also included as a covariate. 
Usual intake (UI) determinations represent long term average daily intakes and were determined by removing excessive intra-person variation in intakes; these are the best estimates to compare to dietary recommendations as suggested intakes are to be met over time, rather than measured on a single day. Usual intake of almond consumption and selected nutrients was determined using the National Cancer Institute (NCI) method [44]. Usual intakes were determined using SAS v 9.2 (SAS Institute, Cary, NC). For UI of almonds, which are consumed episodically, the two part NCI model (probability and amount) was used; for nutrients which are consumed daily by most people, the one part model was used. The NCI SAS macros (Mixtran v1.1 and Distrib v1.1) were used to generate parameter effects after covariate adjustments and to estimate the distribution of UI via Monte Carlo simulation methods, respectively [44]. Covariates in this study were day of the week of the 24-hr recall [coded as weekend (Friday-Sunday) or weekday (Monday-Thursday)] and sequence of dietary recall (first or second). Software provided by NCI was used with the two days of intake using one-day sampling weights to obtain appropriate variance estimates. Balanced repeated replication (BRR) was performed to obtain standard errors and confidence intervals for the percentiles; BRR weights were constructed with Fay adjustment factor $\mathrm{M}=0.3$ (perturbation factor 0.7) and further adjusted to match the initial sample weight totals within specific age/gender/ethnicity groupings for the full dataset. The Dietary Reference Intake (DRI) age groups were used to present UI for each nutrient studied.

To assess the extent of inadequate intake of nutrients with an Estimated Average Requirements (EAR), the cut-point method proposed by the Institute of Medicine [45] was used. The EAR is the appropriate DRI to use when assessing the adequacy of group intakes [45] [46]. The EAR cut-point method provides an estimate of the proportion of individuals in the group with inadequate intakes by age and gender. For nutrients without an EAR, i.e. dietary fiber, sodium, and potassium, the percent above the Adequate Intake (AI) was determined. To determine if there were significant differences for the percentage of almond consumers vs. non-consumers with intakes less than the EAR or above the AI a Z-statistic for differences in population proportions was used. A $p<$ 0.01 was considered significant.

\section{Results}

\subsection{Demographics and Almond Consumption}

Subjects were adults 19+ y ( $\mathrm{N}=24,808$; 49\% female) participating in the NHANES 2001-2010. Almond consumers were more likely $(p<0.01)$ to be non-Hispanic white, older, of higher income, more physically active, and were less likely to be a current smoker than non-consumers (Table 1). Approximately 1.6\% of the population was almond consumers. Per captia consumption was $0.6 \pm 0.03$ g/day (d) $(0.148$ ounces/week) and consumption in almond consumers was $29.5 \pm 1.5 \mathrm{~g} / \mathrm{d}$ (7.284 ounces/week).

Table 1. Demographics of adults 19+ years $(\mathrm{N}=24,808)$ participating in NHANES 2001-2010 by almond consumption.

\begin{tabular}{|c|c|c|c|}
\hline Variable & $\begin{array}{l}\text { Consumers }(\mathrm{n}=395) \\
\mathrm{LSM} \pm \mathrm{SE}\end{array}$ & $\begin{array}{c}\text { Non-Consumers }(\mathrm{n}=24,413) \\
\mathrm{LSM} \pm \mathrm{SE}\end{array}$ & P-Value \\
\hline \multicolumn{4}{|l|}{ Gender (\%) } \\
\hline Female & $62.53 \pm 2.91$ & $50.61 \pm 0.34$ & $<0.0001$ \\
\hline \multicolumn{4}{|l|}{ Ethnicity (\%) } \\
\hline Non-Hispanic White & $84.28 \pm 2.03$ & $71.12 \pm 1.45$ & $<0.0001$ \\
\hline Non-Hispanic Black & $3.68 \pm 1.01$ & $11.47 \pm 0.78$ & $<0.0001$ \\
\hline Mexican-American & $4.89 \pm 0.94$ & $7.90 \pm 0.72$ & 0.0113 \\
\hline Age (Years) & $51.59 \pm 1.01$ & $46.36 \pm 0.25$ & $<0.0001$ \\
\hline Poverty Income Ratio & $3.96 \pm 0.10$ & $2.99 \pm 0.03$ & $<0.0001$ \\
\hline \multicolumn{4}{|l|}{ Physical Activity (\%) } \\
\hline Sedentary & $12.08 \pm 1.94$ & $29.33 \pm 0.60$ & $<0.0001$ \\
\hline Moderate & $34.54 \pm 2.98$ & $34.09 \pm 0.48$ & 0.8836 \\
\hline Active & $53.38 \pm 3.22$ & $36.58 \pm 0.73$ & $<0.0001$ \\
\hline Smoker, current (\%) & $8.54 \pm 1.96$ & $24.58 \pm 0.56$ & $<0.0001$ \\
\hline Alcohol (g) & $10.48 \pm 1.37$ & $11.04 \pm 0.33$ & 0.6919 \\
\hline
\end{tabular}




\subsection{Intake of Protein, Dietary Fiber, and Selected Micronutrients}

Almond consumers had higher $(p<0.01)$ intakes of protein, dietary fiber, total fat, MUFA, and polyunsaturated fatty acids (PUFA) than non-consumers (Table 2). Almond consumers also had lower $(p<0.01)$ intakes of total and added sugars and SFA than non-consumers (Table 2). Usual intake of vitamins A, D, E, and C; riboflavin; folate, calcium, copper, magnesium, iron, and phosphorus were all higher $(p<0.01)$ in almond consumers compared with non-consumers (Table 3). Table 4 shows that UI of dietary fiber and potassium were higher $(p<$ 0.01 ) in almond consumers compared with non-consumers.

\subsection{Nutrient Adequacy}

Table 4 shows that almond consumers were less likely $(p<0.01)$ to be below the EAR for protein, vitamins A, $\mathrm{E}$, and C; riboflavin; calcium; copper; magnesium; phosphorus; and zinc. Almond consumers were also more likely $(p<0.01)$ to be above the AI for dietary fiber (Table 4) than non-consumers.

\subsection{Diet Quality}

Total HEI-2010 scores were approximately 15 points higher in almond consumers (62.46 \pm 0.86$)$ than in non-consumers $(46.61 \pm 0.22)(p<0.01)$ (Table 5). In almond consumers, higher $(p<0.01)$ component scores were seen for every individual component of the HEI-2010, except dairy, when compared with non-consumers. It should be noted that component scores 10 (sodium), 11 (refined grains), and 12 (empty calories) are reverse scored, that is the higher the score, the greater the contribution to diet quality.

\subsection{Anthropometric Measures}

Body mass index was significantly lower $(p<0.01)$ in almond consumers $(27.1 \pm 0.34 \mathrm{v} 28.4 \pm 0.08)$ than in non-consumers, respectively. Waist circumference was also significantly lower $(p<0.01)$ in almond consumers $(94.1 \pm 0.9 \mathrm{v} 97.5 \pm 0.2 \mathrm{~cm})$ than in non-consumers, respectively.

\section{Discussion}

This is the only published epidemiologic study showing the association between nutrient intake, diet quality, and weight/adiposity parameters in almond consumers that we were able to find. Almond consumption was associated with better nutrient intake, dietary adequacy, and diet quality than seen in non-consumers. Weight and adiposity measures were also lower in almond consumers.

Table 2. Least-square mean macronutrient nutrient intake \pm SE in adults 19+ years participating in NHANES 2001-2010 by almond consumption status.

\begin{tabular}{|c|c|c|c|}
\hline Variable $e^{1,2}$ & Consumers LSM $\pm \mathrm{SE}$ & Non-Consumers LSM $\pm \mathrm{SE}$ & $P$-Value \\
\hline Energy (kcal) & $2286.7 \pm 51.8$ & $2176.0 \pm 9.4$ & 0.0414 \\
\hline Protein (gm) & $91.3 \pm 1.7$ & $83.0 \pm 0.3$ & $<0.0001$ \\
\hline Total sugars (gm) & $113.1 \pm 3.8$ & $123.3 \pm 0.8$ & 0.0081 \\
\hline Added sugars (tsp eq) & $14.5 \pm 0.8$ & $19.2 \pm 0.2$ & $<0.0001$ \\
\hline Dietary fiber (gm) & $22.1 \pm 0.7$ & $15.9 \pm 0.1$ & $<0.0001$ \\
\hline Total fat (gm) & $87.6 \pm 1.8$ & $82.2 \pm 0.3$ & 0.0042 \\
\hline SFA (gm) & $24.2 \pm 0.8$ & $27.1 \pm 0.1$ & 0.0005 \\
\hline MUFA (gm) & $35.1 \pm 0.6$ & $30.2 \pm 0.1$ & $<0.0001$ \\
\hline PUFA (gm) & $20.8 \pm 0.9$ & $17.4 \pm 0.1$ & $<0.0001$ \\
\hline Cholesterol (mg) & $284.5 \pm 16.4$ & $287.4 \pm 2.1$ & 0.8604 \\
\hline
\end{tabular}

Data Source: Participants 19 years and older of the NHANES 2003-2010. ${ }^{1}$ Covariates for energy: ethnicity, age, poverty income ratio, physical activity, smoker status, alcohol. ${ }^{2}$ Covariates for nutrients: ethnicity, age, poverty income ratio, physical activity, smoker status, alcohol, and energy (kcals). Abbreviations: SFA = saturated fatty acids; MUFA = mono-unsaturated fatty acids; PUFA = poly-unsaturated fatty acids. 
Table 3. Usual intake ${ }^{1}$ and estimated average intake of protein and selected micronutrient among adult consumers ( $\left.\mathrm{n}=395\right)$ and non-consumers $(n=24,414)$ of Almonds.

\begin{tabular}{|c|c|c|c|c|c|c|c|c|c|c|}
\hline \multirow{2}{*}{ Variable } & \multirow{2}{*}{$\begin{array}{l}\text { Almond } \\
\text { Consumption } \\
\text { Group }\end{array}$} & \multicolumn{2}{|l|}{ Usual Intake } & \multicolumn{5}{|c|}{ Percentile } & \multicolumn{2}{|l|}{ EAR } \\
\hline & & Mean \pm SE & $\mathrm{P}$ & 10 & 25 & 50 & 75 & 90 & $\%$ Below \pm SE & $P$ \\
\hline \multirow{2}{*}{$\begin{array}{l}\text { Protein } \\
\text { (gm) }\end{array}$} & Consumer & $92.3 \pm 2.6$ & 0.0002 & 56.4 & 68.3 & 86.1 & 110.6 & 136.5 & $0.6 \pm 0.4$ & 0.0058 \\
\hline & Non-Consumer & $82.5 \pm 0.4$ & & 51.1 & 62.7 & 78.7 & 98.9 & 119.6 & $2.0 \pm 0.2$ & \\
\hline \multirow{2}{*}{$\begin{array}{l}\text { Vitamin A, } \\
\text { RAE (mcg) }\end{array}$} & Consumer & $803.1 \pm 35.2$ & $<0.0001$ & 472.6 & 594.0 & 759.1 & 963.1 & 1183.8 & $17.9 \pm 4.7$ & $<0.0001$ \\
\hline & Non-Consumer & $606.9 \pm 6.4$ & & 291.2 & 401.6 & 558.7 & 759.6 & 983.4 & $49.8 \pm 0.9$ & \\
\hline \multirow{2}{*}{$\begin{array}{c}\text { Vitamin } \\
\mathrm{D}^{2}(\mathrm{mcg})\end{array}$} & Consumer & $6.1 \pm 0.6$ & 0.0065 & 2.5 & 3.8 & 5.5 & 7.7 & 10.3 & $88.9 \pm 4.7$ & 0.1544 \\
\hline & Non-Consumer & $4.6 \pm 0.1$ & & 1.7 & 2.6 & 4.0 & 5.9 & 8.1 & $95.6 \pm 0.3$ & \\
\hline \multirow{2}{*}{$\begin{array}{l}\text { Vitamin } \\
\mathrm{E}^{3}(\mathrm{mg})\end{array}$} & Consumer & $17.0 \pm 0.9$ & $<0.0001$ & 9.6 & 12.3 & 16.1 & 20.8 & 25.6 & $23.3 \pm 5.2$ & $<0.0001$ \\
\hline & Non-Consumer & $7.2 \pm 0.1$ & & 4.1 & 5.2 & 6.8 & 8.8 & 10.9 & $94.1 \pm 0.4$ & \\
\hline \multirow{2}{*}{$\begin{array}{l}\text { Thiamin } \\
\text { (mg) }\end{array}$} & Consumer & $1.8 \pm 0.1$ & 0.0482 & 1.0 & 1.3 & 1.7 & 2.2 & 2.7 & $7.4 \pm 2.1$ & 0.5860 \\
\hline & Non-Consumer & $1.7 \pm 0.01$ & & 1.0 & 1.2 & 1.6 & 2.0 & 2.4 & $6.3 \pm 0.4$ & \\
\hline \multirow{2}{*}{$\begin{array}{l}\text { Niacin } \\
\text { (mg) }\end{array}$} & Consumer & $26.7 \pm 0.9$ & 0.0339 & 15.6 & 19.5 & 25.2 & 32.5 & 39.8 & $1.3 \pm 0.9$ & 0.5718 \\
\hline & Non-Consumer & $24.8 \pm 0.2$ & & 14.9 & 18.5 & 23.5 & 29.9 & 36.5 & $1.8 \pm 0.3$ & \\
\hline \multirow{2}{*}{$\begin{array}{l}\text { Riboflavin } \\
\text { (mg) }\end{array}$} & Consumer & $2.6 \pm 0.1$ & $<0.0001$ & 1.6 & 2.0 & 2.6 & 3.2 & 3.7 & $0.1 \pm 0.1$ & $<0.0001$ \\
\hline & Non-Consumer & $2.2 \pm 0.01$ & & 1.3 & 1.6 & 2.1 & 2.7 & 3.3 & $2.4 \pm 0.2$ & \\
\hline \multirow{2}{*}{$\begin{array}{c}\text { Folate, } \\
\text { DFE (mcg) }\end{array}$} & Consumer & $603.9 \pm 20.7$ & 0.0053 & 336.1 & 430.6 & 563.5 & 732.7 & 923.5 & $7.9 \pm 7.6$ & 0.6431 \\
\hline & Non-Consumer & $544.9 \pm 4.5$ & & 309.7 & 395.2 & 513.4 & 660.5 & 820.6 & $11.5 \pm 0.5$ & \\
\hline \multirow{2}{*}{$\begin{array}{c}\text { Vitamin } \\
\mathrm{B}_{12}(\mathrm{mcg})\end{array}$} & Consumer & $5.8 \pm 0.3$ & 0.0847 & 2.9 & 3.8 & 5.2 & 7.2 & 9.4 & $2.7 \pm 1.4$ & 0.5218 \\
\hline & Non-Consumer & $5.2 \pm 0.1$ & & 2.6 & 3.5 & 4.8 & 6.5 & 8.4 & $3.6 \pm 0.3$ & \\
\hline \multirow{2}{*}{$\begin{array}{l}\text { Vitamin } \\
\text { C (mg) }\end{array}$} & Consumer & $109.8 \pm 4.9$ & $<0.0001$ & 49.1 & 70.6 & 101.1 & 139.3 & 181.3 & $20.1 \pm 3.8$ & $<0.0001$ \\
\hline & Non-Consumer & $86.3 \pm 1.1$ & & 31.8 & 48.7 & 74.9 & 111.3 & 154.9 & $42.6 \pm 1.0$ & \\
\hline \multirow{2}{*}{$\begin{array}{l}\text { Calcium } \\
\text { (mg) }\end{array}$} & Consumer & $1126.3 \pm 41.8$ & $<0.0001$ & 705.6 & 874.6 & 1093.2 & 1340.7 & 1590.7 & $27.4 \pm 3.5$ & $<0.0001$ \\
\hline & Non-Consumer & $922.8 \pm 6.2$ & & 503.6 & 655.3 & 865.3 & 1126.9 & 1415.3 & $47.9 \pm 0.7$ & \\
\hline \multirow{2}{*}{$\begin{array}{l}\text { Copper } \\
\text { (mg) }\end{array}$} & Consumer & $1.9 \pm 0.1$ & $<0.0001$ & 1.1 & 1.4 & 1.8 & 2.2 & 2.7 & $0.4 \pm 0.2$ & $<0.0001$ \\
\hline & Non-Consumer & $1.3 \pm 0.01$ & & 0.8 & 1.0 & 1.2 & 1.6 & 1.9 & $4.7 \pm 0.4$ & \\
\hline \multirow{2}{*}{$\begin{array}{l}\text { Magnesium } \\
\text { (mg) }\end{array}$} & Consumer & $427.3 \pm 13.7$ & $<0.0001$ & 270.7 & 331.4 & 412.9 & 507.7 & 602.2 & $11.3 \pm 2.2$ & $<0.0001$ \\
\hline & Non-Consumer & $289.5 \pm 2.0$ & & 176.7 & 219.5 & 276.7 & 345.9 & 418.9 & $60.8 \pm 0.9$ & \\
\hline \multirow{2}{*}{$\begin{array}{l}\text { Iron } \\
\text { (mg) }\end{array}$} & Consumer & $17.8 \pm 0.6$ & $<0.0001$ & 10.3 & 12.9 & 16.6 & 21.4 & 26.84 & $6.6 \pm 1.01$ & 0.1262 \\
\hline & Non-Consumer & $15.6 \pm 0.1$ & & 9.3 & 11.6 & 14.8 & 18.7 & 22.93 & $8.2 \pm 0.3$ & \\
\hline \multirow{2}{*}{$\begin{array}{l}\text { Phosphorus } \\
\text { (mg) }\end{array}$} & Consumer & $1584.7 \pm 65.6$ & 0.0003 & 1003.7 & 1207.2 & 1492.6 & 1870.9 & 2294.4 & $0.1 \pm 0.1$ & $<0.0001$ \\
\hline & Non-Consumer & $1347.9 \pm 6.7$ & & 829.1 & 1025.4 & 1288.5 & 1610.8 & 1949.4 & $1.3 \pm 0.2$ & \\
\hline \multirow{2}{*}{$\begin{array}{l}\text { Selenium } \\
\text { (mcg) }\end{array}$} & Consumer & $116.4 \pm 4.1$ & 0.1170 & 63.9 & 82.5 & 111.8 & 146.0 & 174.7 & $1.5 \pm 0.7$ & 0.2141 \\
\hline & Non-Consumer & $110.0 \pm 0.6$ & & 68.2 & 83.6 & 104.9 & 131.5 & 159.0 & $0.7 \pm 0.1$ & \\
\hline \multirow{2}{*}{$\begin{array}{l}\text { Zinc } \\
\text { (mg) }\end{array}$} & Consumer & $13.1 \pm 0.6$ & 0.0980 & 8.0 & 9.7 & 12.2 & 15.6 & 19.4 & $5.4 \pm 2.2$ & 0.0012 \\
\hline & Non-Consumer & $12.1 \pm 0.1$ & & 7.1 & 8.9 & 11.4 & 14.5 & 18.0 & $12.8 \pm 0.6$ & \\
\hline
\end{tabular}

Data Source: Participants 19 years and older of the NHANES 2003-2010. Covariates: ethnicity, age, poverty income ratio, physical activity, smoker status, alcohol, and energy (kcals). Abbreviations: EAR = Estimated Average Requirement; AI = Adequate Intake; RAE = retinol activity equivalents; DFE = dietary folate equivalent. ${ }^{1}$ Excludes Supplement Use; ${ }^{2}$ Vitamin D (D2 + D3) (mcg); ${ }^{3}$ Vitamin E as $\alpha$-tocopherol (mg). 
Table 4. Usual intake ${ }^{1}$ and adequate intake of protein and selected micronutrient among adult consumers $(\mathrm{n}=395)$ and nonconsumers $(n=24,414)$ of almonds.

\begin{tabular}{|c|c|c|c|c|c|c|c|c|c|c|}
\hline \multirow{2}{*}{ Variable } & \multirow{2}{*}{$\begin{array}{l}\text { Almond } \\
\text { Consumption } \\
\text { Group }\end{array}$} & \multicolumn{2}{|l|}{ Usual Intake } & \multicolumn{5}{|c|}{ Percentile } & \multicolumn{2}{|l|}{ AI } \\
\hline & & Mean \pm SE & $\mathrm{P}$ & 10 & 25 & 50 & 75 & 90 & $\%$ Above \pm SE & $P$ \\
\hline \multirow{2}{*}{$\begin{array}{l}\text { Dietary fiber } \\
\quad \text { (gm) }\end{array}$} & Consumer & $23.7 \pm 0.8$ & $<0.0001$ & 14.5 & 17.9 & 22.8 & 28.6 & 35.0 & $33.7 \pm 4.3$ & $<0.0001$ \\
\hline & Non-Consumer & $15.9 \pm 0.1$ & & 8.9 & 11.6 & 15.1 & 19.3 & 23.8 & $4.0 \pm 0.3$ & \\
\hline \multirow{2}{*}{ Sodium (mg) } & Consumer & $3401.1 \pm 100.0$ & 0.1848 & 2218.7 & 2675.6 & 3389.8 & 4170.9 & 4822.4 & $99.9 \pm 0.2$ & 0.2992 \\
\hline & Non-Consumer & $3626.6 \pm 17.6$ & & 2249.6 & 2755.6 & 3448.9 & 4308.3 & 5201.4 & $99.6 \pm 0.1$ & \\
\hline \multirow{2}{*}{$\begin{array}{l}\text { Potassium } \\
\quad(\mathrm{mg})\end{array}$} & Consumer & $3271.5 \pm 86.4$ & $<0.0001$ & 2154.5 & 2610.1 & 3210.8 & 3901.6 & 4610.0 & $8.7 \pm 2.6$ & 0.0125 \\
\hline & Non-Consumer & $2715.4 \pm 15.5$ & & 1675.3 & 2080.4 & 2606.8 & 3227.6 & 3868.0 & $2.4 \pm 0.2$ & \\
\hline \multirow{2}{*}{ Total Choline } & Consumer & $342.9 \pm 13.6$ & 0.2981 & 209.7 & 261.3 & 342.3 & 421.7 & 483.7 & $6.6 \pm 3.2$ & 0.8998 \\
\hline & Non-Consumer & $333.4 \pm 1.9$ & & 197.3 & 244.4 & 311.1 & 397.7 & 490.3 & $6.2 \pm 0.4$ & \\
\hline
\end{tabular}

Data Source: Participants 19 years and older of the NHANES 2003-2010. Covariates: ethnicity, age, poverty income ratio, physical activity, smoker status, alcohol, and energy (kcals). Abbreviations: AI = Adequate Intake. ${ }^{1}$ Excludes Supplement Use.

Table 5. Mean total Healthy Eating Index-2010 (HEI) and component scores \pm SE in adults 19+ years participating in NHANES 2001-2010 by almond consumption category.

\begin{tabular}{cccc}
\hline Variable & Consumers & Non-Consumers & $P$ \\
\cline { 2 - 3 } HEI-2010 Total Score & LSM \pm SE & LSM \pm SE & $<0.0001$ \\
Component 1 (Total Vegetables) & $62.5 \pm 0.9$ & $46.6 \pm 0.2$ & $<0.0001$ \\
Component 2 (Greens and Beans) & $3.4 \pm 0.1$ & $3.1 \pm 0.02$ & 0.0003 \\
Component 3 (Total Fruit) & $1.7 \pm 0.2$ & $1.1 \pm 0.02$ & $<0.0001$ \\
Component 4 (Whole Fruit) & $3.0 \pm 0.1$ & $2.2 \pm 0.03$ & $<0.0001$ \\
Component 5 (Whole Grains) & $3.0 \pm 0.2$ & $2.0 \pm 0.03$ & 0.0026 \\
Component 6 (Dairy) & $2.9 \pm 0.2$ & $2.1 \pm 0.04$ & 0.0473 \\
Component 7 (Total Protein Foods) & $5.4 \pm 0.2$ & $4.9 \pm 0.1$ & $<0.0001$ \\
Component 8 (Seafood and Plant Protein) & $4.7 \pm 0.1$ & $1.1 \pm 0.02$ & $<0.0001$ \\
Component 9 (Fatty Acid Ratio) & $4.3 \pm 0.1$ & $4.8 \pm 0.04$ & $<0.0001$ \\
Component 10 (Sodium) & $7.4 \pm 0.2$ & $4.2 \pm 0.04$ & 0.0039 \\
Component 11 (Refined Grains) & $5.0 \pm 0.3$ & $5.9 \pm 0.1$ & $10.3 \pm 0.1$ \\
Component 12 (Empty Calories) & $7.5 \pm 0.2$ & $14.2 \pm 0.4$ & $<0.0001$ \\
\end{tabular}

Covariates: Gender, ethnicity, age, poverty income ratio (PIR 0 - 1.25, 1.25 - 3.5, ⒊50), physical activity level (sedentary, moderate, active), current smoking status.

According to the Economic Research Service of the USDA [3], almonds have the highest per captia utilization of the tree nuts. This study showed that only approximately $1.6 \%$ of the study population consumed almonds; however, this percentage still represents over 2 million individuals. On average, almond consumers easily met the DGA recommendation for nuts and seeds of 2 to 8 ounces of total nuts per week [6]. Further studies are needed to determine the extent to which the population on the whole is meeting this recommendation.

Consumption of almonds was associated with higher intake of several nutrients of public health concern [6], including dietary fiber, calcium, and potassium, as well as higher intakes of shortfall nutrients including vitamins A, E, and C; folate; iron and magnesium [18]. These findings are similar to those seen with other tree nuts 
[17]. A limitation of cross-sectional studies, like the NHANES, is that they cannot show a causal association and there is a possibility that since 24-hour dietary recalls are memory dependent, individuals may be spuriously placed in a consumption group. However, Jaceldo-Siegl et al. [22] [26] showed that in a long term feeding trial with almonds, nutrient intake of short-fall and some nutrients to limit also improved.

This study expanded previous epidemiologic studies of tree nuts in which it used UI to determine nutrient adequacy rather than simply nutrient intake and concentrated on the most widely consumed tree nut. The EAR is the appropriate value when assessing groups or individuals; however, the AI is not as effective when assessing nutrient adequacy, since it is used when an EAR is not available [45] [46]. This study showed that almond consumers were less likely to be below the EAR for some nutrients and above the AI for others than non-consumers In this study, mean dietary fiber intake in the population, even among almond consumers, was below the AI level recommended for individuals; however, mean fiber intake among adults in the U.S. was higher than that often reported by US adults [47] [48]. The fiber intake of almond consumers was higher than the fiber content found in the mean amount of almonds consumed, suggesting that other high fiber foods are contributing to overall intake and that almond consumers may have an overall healthier diet than non-consumers. The HEI-2010 component scores suggest that almond consumers had higher intakes of high fiber foods, such as fruit, vegetables, beans and whole grains.

Of particular import is the high intake and better nutrient adequacy for Vitamin E, for which there is a paucity of food sources, seen in almond consumers. The 2005 Dietary Guidelines Advisory Committee (DGAC) [49] identified vitamin E as a shortfall nutrient, whereas the 2010 DGAC did not [50], in part because the role of vitamin E and health was not well established [51]-[53]. The 2010 DGA did find that oil intake fell short of recommended intakes and that vitamin $\mathrm{E}$ was an important nutrient in oils. Vitamin $\mathrm{E}$ is a potent antioxidant with lipoperoxyl radical-scavenging activities [51]-[53]. Most Americans do not consume the recommended amounts of vitamin E [6]. A recent meta-analysis has shown that vitamin E intake alone or combined with other agents reduced all-cause mortality, but low doses of vitamin E combined with other agents may be more efficacious [52].

Diet quality, as measured by HEI-2010, was approximately 15\% higher in almond consumers compared to non-consumers. Almost all component scores of the HEI-2010 were better in almond consumers. Especially notable were seafood and plant protein (component 8), fatty acid ratio (component 9), and empty calories (component 12). Seafood, nuts and seeds, and soy products (except soy milk) are counted in component 8 [39] [40]. This component has a maximum score of 5 and almond consumers score nearly 4.5. The fatty acid ratio is the ratio of PUFA and MUFA to SFA, and reflects the DGA recommendation to replace SFA with MUFA and PUFA [6]. The maximum score for this component is 10 . Almonds have a very favorable lipid profile: a one ounce serving of almonds contains $12.44 \mathrm{~g}$ of unsaturated fatty acids, compared with only $1.02 \mathrm{~g}$ of SFA. Empty calories are defined as those kilocalories from solid fats, alcohol (threshold $>13 \mathrm{~g} / 1000 \mathrm{kcals}$ ), and added sugars; and the maximum score is 20 ( $\leq 19 \%$ of energy) [39]; almond consumers have a score of 14.15 . Other component scores of the HEI-2010, which were also higher in almond consumers, such as total vegetables, greens and beans, and total/whole fruit, are not directly linked with almonds, suggesting that almond consumers may have a healthier diet than non-consumers. The demographic data also suggest that almond consumers may have an overall healthier lifestyle with a higher percentage of physical activity and a lower percentage of smoking. Recently, it is suggested that nut consumers, in general, have a healthier lifestyle than non-consumers [54]; however, this has not been shown for almond consumers.

There has been hesitancy about recommending the inclusion of almonds (and other tree nuts) in the diet because it has been speculated that their high energy and fat content could cause weight gain [55]; although more recent studies have suggested that the energy content of almonds is less than previously thought [11]. Since NHANES is a cross-sectional study, weight gain cannot be determined; however, almond consumers had lower mean BMI and WC values than non-consumers. Although some epidemiologic studies have shown higher energy intake among tree nut consumers [17], although this study did not, the same studies have also shown an inverse relationship with weight parameters [17] [19]; other studies have shown that the participants were at lower risk for obesity [56]. Potential reasons for this are the proposed usable energy content [11], high satiety value that almonds provide, coupled with energy compensation [25], and raising resting energy metabolism [25]. Similar epidemiologic studies have not been conducted in almond consumers; however, long term intervention studies have shown that almond consumption was not associated with lower weights or with weight gain [4] [5] [26]. Another study showed that, although those consuming an almond-enriched hypoenergetic diet lost weight, 
they did not lose as much weight as those consuming a nut-free hypoenergetic diet [23]. Thus, additional studies evaluating weight and almond consumption are needed.

The strengths of this study are that it used a large, nationally representative population. In addition, UI was calculated so that nutrient adequacy, in addition to nutrient intake, could be determined. The limitations of this study are that NHANES is a cross-sectional study; thus, causal inferences cannot be drawn. Twenty-hour dietary recalls have several inherent limitations: they are memory dependent and subjects may over- or under-report energy intake. Further, while we adjusted for numerous covariates, differences described might be due to residual confounding. Lastly, there is a possibility that almond consumers were misclassified.

In conclusion, consumption of almonds was associated with nutrient intake, nutrient adequacy, better diet quality, and better weight parameters than those seen in non-consumers. It is likely that almonds contributed to these results and to an overall healthy diet. Thus, consumption of almonds should be included as part of a healthy diet.

\section{Acknowledgements}

This research project was supported by the Almond Board of California and USDA-Agricultural Research Service through specific cooperative agreement 58-6250-0-008. Partial support was received from the USDA Hatch Project LAB 93951. The funding agencies had no input into the study design or data interpretation. The authors declare no conflicts of interest.

This work is a publication of the United States Department of Agriculture (USDA/ARS) Children's Nutrition Research Center, Department of Pediatrics, Baylor College of Medicine, Houston, Texas. The contents of this publication do not necessarily reflect the views or policies of the USDA, nor does mention of trade names, commercial products, or organizations imply endorsement from the U.S. government.

\section{References}

[1] Gradziel, T. (2011) Origin and Dissemination of Almond. In: Hoboken, J.J., Ed., Horticultural Reviews. Vol. 38, John Wiley \& Sons, Inc., Hoboken, 23-81. http://dx.doi.org/10.1002/9780470872376.ch2

[2] 2013 Almond Almanac. Almond Board of California. http://www.almonds.com/sites/default/files/content/attachments/2013_almanac.pdf.

[3] United States Department of Agriculture. Economic Research Service. Fruit and Tree Nuts Yearbook Tables. Table F-8. Almond: Supply and Utilization (Shelled Basis), 1980/81 to Date. http://www.ers.usda.gov/data-products/fruit-and-tree-nut-data/yearbook-tables.aspx\#40907.

[4] Tan, S.Y. and Mattes, R.D. (2013) Appetitive, Dietary and Health Effects of Almonds Consumed with Meals or as Snacks: A Randomized, Controlled Trial. European Journal of Clinical Nutrition, 67, 1205-1214. http://dx.doi.org/10.1038/ejcn.2013.184

[5] Zaveri, S. and Drummond, S. (2009) The Effect of Including a Conventional Snack (Cereal Bar) and a Nonconventional Snack (Almonds) on Hunger, Eating Frequency, Dietary Intake and Body Weight. Journal of Human Nutrition and Dietetics, 22, 461-468. http://dx.doi.org/10.1111/j.1365-277X.2009.00983.X

[6] Dietary Guidelines for Americans 2010. http://health.gov/dietaryguidelines/dga2010/DietaryGuidelines2010.pdf

[7] United States Food and Drug Administration. Guidance for Industry: A Food Labeling Guide (14. Appendix F: Calculate the Percent Daily Value for the Appropriate Nutrients).

http://www.fda.gov/Food/GuidanceRegulation/GuidanceDocumentsRegulatoryInformation/LabelingNutrition/ucm064 928.htm.

[8] USDA National Nutrient Database for Standard Reference. Release 27. http://ndb.nal.usda.gov

[9] Traoret, C.J., Lokko, P., Cruz, A.C., Oliveira, C.G., Costa, N.M., et al. (2008) Peanut Digestion and Energy Balance. International Journal of Obesity, 32, 322-328. http://dx.doi.org/10.1038/sj.ijo.0803735

[10] Berry, S.E., Tydeman, E.A., Lewis, H.B., Phalora, R., Rosborough, J., et al. (2008) Manipulation of Lipid Bioaccessibility of Almond Seeds Influences Postprandial Lipemia in Healthy Human Subjects. The American Journal of Clinical Nutrition, 88, 922-929.

[11] Novotny, J.A., Gebauer, S.K. and Baer, D.J. (2012) Discrepancy between the Atwater Factor Predicted and Empirically Measured Energy Values of Almonds in Human Diets. The American Journal of Clinical Nutrition, 96, $296-301$. http://dx.doi.org/10.3945/ajcn.112.035782

[12] Bolling, B.W., Chen, C.Y., McKay, D.L. and Blumberg, J.B. (2011) Tree Nut Phytochemicals: Composition, Antioxi- 
dant Capacity, Bioactivity, Impact Factors. A Systematic Review of Almonds, Brazils, Cashews, Hazelnuts, Macadamias, Pecans, Pine Nuts, Pistachios and Walnuts. Nutrition Research Reviews, 24, 244-275. http://dx.doi.org/10.1017/S095442241100014X

[13] Bolling, B.W., Dolnikowski, G., Blumberg, J.B. and Oliver Chen, C.Y. (2009) Quantification of Almond Skin Polyphenols by Liquid Chromatography-Mass Spectrometry. Journal of Food Science, 74, C326-C332. http://dx.doi.org/10.1111/j.1750-3841.2009.01133.x

[14] Xie, L., Roto, A.V. and Bolling, B.W. (2012) Characterization of Ellagitannins, Gallotannins, and Bound Proanthocyanidins from California Almond (Prunus dulcis) Varieties. Journal of Agricultural and Food Chemistry, 60, 1215112156. http://dx.doi.org/10.1021/jf303673r

[15] United States Food and Drug Administration. Summary of Qualified Health Claims Subject to Enforcement Discretion. http://www.fda.gov/food/ingredientspackaginglabeling/labelingnutrition/ucm073992.htm\#nuts

[16] Dietary Guidelines for Americans 2005. http://www.health.gov/dietaryguidelines/dga2005/document

[17] O’Neil, C.E., Keast, D.R., Nicklas, T.A. and Fulgoni III, V.L. (2012) Out-of-Hand Nut Consumption Is Associated with Improved Nutrient Intake and Health Risk Markers in US Children and Adults: National Health and Nutrition Examination Survey 1999-2004. Nutrition Research, 32, 185-194. http://dx.doi.org/10.1016/j.nutres.2012.01.005

[18] O’Neil, C.E., Keast, D.R., Fulgoni, V.L. and Nicklas, T.A. (2010) Tree Nut Consumption Improves Nutrient Intake and Diet Quality in US Adults: An Analysis of National Health and Nutrition Examination Survey (NHANES) 1999-2004. Asia Pacific Journal of Clinical Nutrition, 19, 142-150.

[19] O’Neil, C.E., Keast, D.R., Nicklas, T.A. and Fulgoni III, V.L. (2011) Nut Consumption Is Associated with Decreased Health Risk Factors for Cardiovascular Disease and Metabolic Syndrome in US Adults: NHANES 1999-2004. The Journal of the American College of Nutrition, 30, 502-510. http://dx.doi.org/10.1080/07315724.2011.10719996

[20] Martínez-González, M.A. and Bes-Rastrollo, M. (2011) Nut Consumption, Weight Gain and Obesity: Epidemiological Evidence. Nutrition Metabolism and Cardiovascular Diseases, 21, S40-S45. http://dx.doi.org/10.1016/j.numecd.2010.11.005

[21] Mattes, R.D., Kris-Etherton, P.M. and Foster, G.D. (2008) Impact of Peanuts and Tree Nuts on Body Weight and Healthy Weight Loss in Adults. Journal of Nutrition, 138, 1741S-1745S.

[22] Jaceldo-Siegl, K., Sabaté, J., Rajaram, S. and Fraser, G.E. (2004) Long-Term Almond Supplementation without Advice on Food Replacement Induces Favourable Nutrient Modifications to the Habitual Diets of Free-Living Individuals. British Journal of Nutrition, 92, 533-540. http://dx.doi.org/10.1079/BJN20041223

[23] Foster, G.D., Shantz, K.L., Vander Veur, S.S., Oliver, T.L. and Lent, M.R. (2012) A Randomized Trial of the Effects of an Almond-Enriched, Hypocaloric Diet in the Treatment of Obesity. The American Journal of Clinical Nutrition, 96, 249-254. http://dx.doi.org/10.3945/ajcn.112.037895

[24] Fraser, G.E., Bennett, H.W., Jaceldo, K.B. and Sabaté, J. (2002) Effect on Body Weight of a Free 76 Kilojoule (320 calorie) Daily Supplement of Almonds for Six Months. Journal of the American College of Nutrition, 21, 275-283. http://dx.doi.org/10.1080/07315724.2002.10719221

[25] Hollis, J. and Mattes, R. (2007) Effect of Chronic Consumption of Almonds on Body Weight in Healthy Humans. British Journal of Nutrition, 98, 651-656. http://dx.doi.org/10.1017/S0007114507734608

[26] Jaceldo-Siegl, K., Sabaté, J., Batech, M. and Fraser, G.E. (2011) Influence of Body Mass Index and Serum Lipids on the Cholesterol-Lowering Effects of Almonds in Free-Living Individuals. Nutrition Metabolism and Cardiovascular Diseases, 21, S7-S13. http://dx.doi.org/10.1016/j.numecd.2011.03.007

[27] Centers for Disease Control and Prevention. National Center for Health Statistics, National Health and Nutrition Examination Survey Analytic Guidelines. http://www.cdc.gpv/nchs/nhanes/survey_methods.htm

[28] National Health and Nutrition Examination Survey. Analytic Note Regarding 2007-2010 Survey Design Changes and Combining Data across Other Survey Cycles. http://www.cdc.gov/nchs/data/nhanes/analyticnote_2007-2010.pdf

[29] Centers for Disease Control and Prevention (2007) Welcome NHANES Participants: Is My Survey Information Confidential? December, 2007. http://www.cdc.gov/nhanes/pQuestions.htm\#

[30] US Department of Health \& Human Services. Office of Extramural Research. http://grants.nih.gov/grants/policy/hs/hs_policies.htm

[31] National Health and Nutrition Examination Survey 2011-2012 Data Documentation, Codebook, and Frequencies Demographic Variables and Sample Weights (DEMO_G). http://wwwn.cdc.gov/nchs/nhanes/2011-2012/DEMO G.htm

[32] Moshfegh, A.J., Rhodes, D.G., Baer, D.J., Murayi, T. and Clemens, J.C. (2008) The US Department of Agriculture Automated Multiple-Pass Method Reduces Bias in the Collection of Energy Intakes. The American Journal of Clinical Nutrition, 88, 324-332.

[33] Blanton, C.A., Moshfegh, A.J., Baer, D.J. and Kretsch, M.J. (2006) The USDA Automated Multiple-Pass Method Ac- 
curately Estimates Group Total Energy and Nutrient Intake. Journal of Nutrition, 136, 2594-2599.

[34] National Center for Health Statistics: The NHANES 2002 MEC In-Person Dietary Interviewers Procedures Manual. http://www.cdc.gov/nchs/data/nhanes/nhanes_01_02/dietary_year_3.pdf

[35] National Center for Health Statistics: Phone Follow-Up Dietary Interviewer Procedures Manual. http://www.cdc.gov/nchs/data/nhanes/nhanes_03_04/DIETARY_PFU.pdf

[36] National Health and Nutrition Examination Survey. NHANES 2009-2010 Dietary Data. http://wwwn.cdc.gov/nchs/nhanes/search/datapage.aspx?Component=Dietary\&CycleBeginYear=2009

[37] The United States Department of Agriculture. Agricultural Research Service, Food and Nutrient Database for Dietary Studies. http://www.ars.usda.gov/services/docs.htm?docid=12089

[38] United States Department of Agriculture. Agricultural Research Service, Food and Nutrient Database for Dietary Studies, Vitamin D Addendum to USDA Food and Nutrient Database for Dietary Studies 3.0. http://www.ars.usda.gov/News/docs.htm?docid=12068

[39] Guenther, P.M., Casavale, K.O., Reedy, J., Kirkpatrick, S.I. and Hiza, H.A. (2013) Update of the Healthy Eating Index: HEI-2010. Journal of the Academy of Nutrition and Dietetics, 113, 569-580. http://dx.doi.org/10.1016/j.jand.2012.12.016

[40] Guenther, P.M., Kirkpatrick, S.I., Reedy, J., Krebs-Smith, S.M. and Buckman, D.W. (2014) The Healthy Eating Index-2010 Is a Valid and Reliable Measure of Diet Quality according to the 2010 Dietary Guidelines for Americans. Journal of Nutrition, 144, 399-407. http://dx.doi.org/10.3945/jn.113.183079

[41] Center for Nutrition Policy and Promotion. Healthy Eating Index-2010 SAS Program. http://www.cnpp.usda.gov/HealthyEatingIndexSupportFiles0708.htm

[42] National Center for Health Statistics. The NHANES Anthropometry Procedures Manual. http://www.cdc.gov/nchs/data/nhanes/nhanes_03_04/BM.pdf

[43] National Center for Health Statistics. NHANES Documentation, Codebook, and Frequencies: Survey Years 2003-2004, Physical Activity. http://www.cdc.gov/nchs/nhanes/nhanes2005-2006/PAQ D.htm

[44] Usual Dietary Intakes: SAS Macros for Analysis of a Single Dietary Component. http://riskfactor.cancer.gov/diet/usualintakes/macros_single.html

[45] Institute of Medicine (2000) Food and Nutrition Board, Dietary Reference Intakes: Applications in Dietary Assessment. http://www.nap.edu/catalog.php?record_id=9956\&utm_expid=4418042-5.krRTDpXJQISoXLpdo-1Ynw.0\&utm_referr er=http\%3A\%2F\%2F

[46] Murphy, S.P. and Poos, M.I. (2002) Dietary Reference Intakes: Summary of Applications in Dietary Assessment. Public Health Nutrition, 5, 843-849. http://dx.doi.org/10.1079/PHN2002389

[47] Reicks, M., Jonnalagadda, S., Albertson, A.M. and Joshi, N. (2014) Total Dietary Fiber Intakes in the US Population Are Related to Whole Grain Consumption: Results from the National Health and Nutrition Examination Survey 2009 to 2010. Nutrition Research, 34, 226-234. http://dx.doi.org/10.1016/j.nutres.2014.01.002

[48] O’Neil, C.E., Keast, D.R., Fulgoni, V.L. and Nicklas, T.A. (2012) Food Sources of Energy and Nutrients among Adults in the US: NHANES 2003-2006. Nutrients, 4, 2097-2120. http://dx.doi.org/10.3390/nu4122097

[49] United States Department of Health and Human Services (2005) Dietary Guidelines for Americans. The Report of the Dietary Guidelines Advisory Committee on Dietary Guidelines for Americans. http://health.gov/dietaryguidelines/dga2005/report

[50] United States Department of Agriculture (2010) Center for Nutrition Policy and Promotion. Dietary Guideline for Americans. Report of the Dietary Guidelines Advisory Committee on the Dietary Guidelines for Americans. http://www.cnpp.usda.gov/sites/default/files/dietary_guidelines_for_americans/2010DGACReport-camera-ready-Jan11 -11.pdf

[51] Rizvi, S., Raza, S.T., Ahmed, F., Ahmad, A., Abbas, S. and Mahdi, F. (2014) The Role of Vitamin E in Human Health and Some Diseases. Sultan Qaboos University Medical Journal, 14, e157-e165.

[52] Jiang, S., Pan, Z., Li, H., Li, F., Song, Y. and Qiu, Yu. (2014) Meta-Analysis: Low-Dose Intake of Vitamin E Combined with Other Vitamins or Minerals May Decrease All-Cause Mortality. Journal of Nutritional Science and Vitaminology (Tokyo), 60, 194-205.

[53] Jiang, Q. (2014) Natural Forms of Vitamin E: Metabolism, Antioxidant, and Anti-Inflammatory Activities and Their Role in Disease Prevention and Therapy. Free Radical Biology and Medicine, 72, 76-90. http://dx.doi.org/10.1016/j.freeradbiomed.2014.03.035

[54] Bao, Y., Han, J., Hu, F.B., Giovannucci, E.L., Stampfer, M.J., et al. (2013) Association of Nut Consumption with Total and Cause-Specific Mortality. The New England Journal of Medicine, 369, 2001-2011. http://dx.doi.org/10.1056/NEJMoa1307352 
[55] Hu, F.B. and Stampfer, M.J. (1999) Nut Consumption and Risk of Coronary Heart Disease: A Review of Epidemiologic Evidence. Current Atherosclerosis Reports, 1, 204-209. http://dx.doi.org/10.1007/s11883-999-0033-7

[56] Bes-Rastrollo, M., Sabaté, J., Gómez-Gracia, E., Alonso, A. and Martínez, J.A. (2007) Nut Consumption and Weight Gain in a Mediterranean Cohort: The SUN Study. Obesity (Silver Spring), 15, 107-116.

http://dx.doi.org/10.1038/oby.2007.507 